\title{
EL MARCO REGULADOR EN PROYECTO EN ESPAÑA PARA LA RESOLUCIÓN ALTERNATIVA DE CONFLICTOS: ¿NUEVAS PERSPECTIVAS PARA LAS RECLAMACIONES DE CONSUMO?
}

\author{
Nuria MARChAL EsCALONA*
}

SUMARIO: 1. INTRODUCCIÓN.-2. LAS RECLAMACIONES EN EL SECTOR DEL TRANSPORTE AÉREO: LAS LÍNEAS BÁSICAS ESTABLECIDAS EN LA LEY 7/2017. - 3. ANÁLISIS DE LA NUEVA INICIATIVA LEGISLATIVA SOBRE RESOLUCIÓN ALTERNATIVA DE CONSUMO EN EL ÁMBITO DEL TRANSPORTE AÉREO.-3.1. Ámbito de aplicación.-3.2. El procedimiento de resolución de controversias en el ámbito del transporte aéreo.-3.3. La adaptación de la iniciativa proyectada al marco estatal de resolución alternativa de litigios de consumo.-3.3.1. Principios de independencia, imparcialidad y eficacia.-3.3.2. Principios de equidad, libertad y legalidad.-4. HACIA LA «MEDIACIÓN OBLIGATORIA MITIGADA»EN EL SISTEMA JURÍDICO ESPAÑOL.-4.1. Introducción.-4.2. ¿Es viable la mediación extrajudicial de consumo en España?-5. CONCLUSIONES.

\section{INTRODUCCIÓN}

1. A finales del siglo XVIII, Kant señalaba que la más compleja de las tareas de la humanidad era la de administrar justicia ${ }^{1}$. Entonces la sociedad del siglo XVIII era menos compleja y la administración de justicia tenía menos asuntos que tratar. Hoy en día, la sobrecarga de trabajo que aqueja a muchos tribunales conlleva a que no se puedan atender todos los asuntos que tienen asignados y los retrasos en la resolución de los asuntos están a la orden del día. Se precisan de mecanismos alternativos a la jurisdicción

* Profesora Titular de Derecho internacional privado en la Universidad de Granada (nmarchal@ ugr.es). Todas las páginas web de referencia han sido consultadas por última vez el 10 de mayo de 2019. Agradecemos las observaciones realizadas al presente trabajo por F. Esteban de la Rosa, Catedrático de Derecho internacional privado de la Universidad de Granada, cuya responsabilidad es íntegramente de la autora.

1 Hart, K., «Kant, “Antropology” and the New Human Universal», Social Anthropology, vol. 18, 2010, pp. 441-447, cit. por BETANCOURT, J. C., «Reexaminando la noción de resolución alternativa de disputas (ADR) en el contexto del derecho de acceso a la justicia "no jurisdiccional” ", Cuadernos de Derecho Transnacional, vol. 10, 2018, núm. 2, pp. 211-248, esp. p. 237. 
capaces de solucionar conflictos de forma rápida y a un menor coste económico y personal para los interesados, sobre todo, en el ámbito del Derecho de consumo. Vivimos en una era en la que el comercio electrónico, el incremento de las adquisiciones transfronterizas y la necesidad de dotar de eficacia a los derechos reconocidos a los consumidores plantean nuevos retos. Para que un consumidor adquiera bienes y servicios necesita seguridad jurídica. El temor a no saber qué hacer si surge cualquier problema en relación con el producto o servicio adquirido, así como dónde reclamar, especialmente en los supuestos transfronterizos de escasa cuantía, merma la confianza del consumidor a la hora de realizar compras en un mercado que no sea el nacional. Esta circunstancia revela que la efectiva protección del consumidor en el ámbito internacional pasa por la formulación de cauces procesales que satisfagan de forma rápida y eficaz su derecho a la tutela judicial efectiva ${ }^{2}$.

2. Se impone, pues, la exigencia de encontrar mecanismos alternativos y capaces de gestionar de forma efectiva y positiva los conflictos planteados por los consumidores. Consciente de esta situación, el legislador de la Unión Europea (UE) ha dedicado en los últimos tiempos sus esfuerzos a instaurar, normalizar y generalizar la utilización de los sistemas de resolución alternativas de litigios (RAL) y, en particular, a partir de la aprobación de la Directiva 2013/11/UE, del Parlamento Europeo y del Consejo, de 21 de mayo, sobre resolución alternativa de litigios en materia de consumo $\left(\mathrm{DRAL}^{3}\right)$, así como del Reglamento 524/2013, del Parlamento Europeo y del Consejo, de 21 de mayo, sobre resolución de litigios en línea en materia de consumo y por el que se modifica el Reglamento (CE) núm. 2006/2004 y la Directiva 2009/22/ CE (RLL) ${ }^{4}$, que supuso la creación de la Plataforma ODR para la resolución de litigios en línea ${ }^{5}$. De esta manera, mediante el establecimiento de principios obligatorios para los sistemas de resolución alternativa de litigios de consumo y la instauración de la Plataforma Europea ODR, el legislador

2 Marchal Escalona, N., "La protección del consumidor en los litigios transfronterizos de escasa cuantía en la Unión Europea y en América Latina», en EsTEBAN DE LA RosA, F. (ed.), La protección del consumidor en dos espacios de integración: Europa y América. Una perspectiva de Derecho internacional, europeo y comparado, Valencia, Tirant lo Blanch, 2015, pp. 1015-1051, esp. p. 1018; EsTEBAN DE LA Rosa, F., «Desafíos de la contratación electrónica para los sistemas de resolución alternativa de litigios de consumo: radiografía de una transformación necesaria», Revista Jurídica sobre Consumidores y Usuarios. Monográfico sobre Consumidores y Comercio electrónico, 2018, núm. 3, Vlex, pp. 1-15, esp. p. 2.

3 DO L núm. 165, de 18 de junio de 2013.

4 Ibid.; corrección de errores, DO L núm. 219/4, de 29 de agosto de 2018. Se trata de un instrumento legal que complementa a la DRAL [AzcárRaGa Monzonís, C., "Medios electrónicos en los sistemas extrajudiciales de resolución de conflictos», en Palao Moreno, G. (ed.), Azcárraga Mónzonis, C. (secret.), Los nuevos instrumentos europeos en materia de conciliación, mediación y arbitraje de consumo. Su incidencia en España, Irlanda y el Reino Unido, Valencia, Tirant lo Blanch, 2016, p. 29]. A pesar de ello, ambos textos difieren en cuanto al objeto y ámbito de aplicación (CARRIzo AGUADo, D., "Asistencia extrajudicial al consumidor transfronterizo europeo», Cuadernos de Derecho Transnacional, vol. 10, 2018, núm. 1, pp. 45-69).

5 Sobre los aspectos a mejorar de la Plataforma, véase EstebAn DE LA RosA, F., «ADR-Rooted ODR Design in Europe. A Bet for the Future», IJODR, 2018, pp. 1-9. 
europeo pretendía contribuir a impulsar la protección del consumidor y del comercio transfronterizo ${ }^{6}$.

3. El texto de la DRAL fue finalmente transpuesto, al ordenamiento jurídico español con más de dos años de retraso, en virtud de la Ley 7/2017, de 2 de noviembre (Ley 7/2017) ${ }^{7}$. Esta ley representa el primer paso -aunque no el único- en el camino hacia la creación de entidades RAL acreditadas en España, que respondan a los estándares elevados de calidad establecidos por la DRAL (principios de independencia, imparcialidad transparencia, eficacia y equidad). No obstante, este proceso de adaptación está todavía inconcluso. Hay disposiciones que, según la propia Ley 7/2017, deben ser objeto de un posterior desarrollo normativo, como así sucede en el sector financiero (DA 1..$^{a}$ y en el del transporte aéreo (DA 2. $\left.{ }^{a}\right)^{8}$. De hecho, para cumplir con este último mandato, ha sido presentada la Propuesta de Orden por la que se regula el procedimiento de resolución alternativa de litigios en materia de derechos de los usuarios de transporte aéreo establecidos en el ámbito de la Unión Europea (P.Or) ${ }^{9}$.

4. Con la Ley $7 / 2017$, el legislador español pretende garantizar a los consumidores el acceso a los mecanismos de resolución alternativa de litigios en materia de consumo que sean de alta calidad por ser independientes, imparciales, transparentes, efectivos, rápidos y justos (art. 1.1), sin que ello suponga restringir el acceso a los órganos jurisdiccionales. El consumidor no puede ser privado del derecho a la tutela judicial efectiva de conformidad con lo dispuesto en la Carta Europea de Derechos Fundamentales (CEDF) ${ }^{10}$, el Convenio Europeo de los Derechos del Hombre $(\mathrm{CEDH})^{11}$ y el Tratado de Funcionamiento de la Unión Europa (TFUE) ${ }^{12}$.

6 Por otra parte, y de forma paralela a esta iniciativa legislativa, el legislador europeo optó por revisar y modificar el proceso europeo de escasa cuantía regulado en el Reglamento (CE) núm. 861/2007, del Parlamento Europeo y del Consejo, de 11 de julio (DO L núm. 199, de 31 de julio de 2007). Para un análisis del mismo, véase MARchal EscalonA, N., «Las relaciones entre las entidades de RAL de consumo y los sistemas judiciales en las reclamaciones transfronterizas: Especial referencia al proceso europeo de escasa cuantía», en EsTEBAN DE LA RosA, F. (dir.) y OLARIU, O. (coord.), La resolución de conflictos de consumo. La adaptación del Derecho español al marco europeo de resolución alternativa (ADR) y en Línea (ODR), Navarra, Thomson Reuters-Aranzadi, 2018, pp. 509-534, esp. pp. 529-531.

7 No se trata, sin embargo, de la primera norma estatal de transposición de la Directiva, pues a través de la Ley 3/2014, de 27 de marzo (BOE núm. 268, de 4 de noviembre de 2017), se modificó el art. 57.4 del texto refundido de la Ley General para la Defensa de los Consumidores y Usuarios (TRLGDCU), con miras a adaptar la normativa española a lo establecido en el art. 10 DRAL.

8 Además, existen otras disposiciones que precisan de reformas legislativas para adaptarse a la normativa europea, como sucede con el Real Decreto 231/2008, de 15 de febrero, por el que se regula el Sistema Arbitral de Consumo (RDSAC). Al respecto, véase OLARIU, O., «El sistema español de arbitraje de consumo ante su acreditación europea», en EsTEBAN DE LA RosA, F. (dir.) y OlARIU, O. (coord.), La resolución de conflictos de consumo. La adaptación del Derecho español al marco europeo de resolución alternativa $(A D R)$ y en Línea $(O D R)$, Navarra, Thomson Reuters-Aranzadi, 2018, pp. 127-146.

9 https://www.fomento.es/NR/rdonlyres/2D5A3CF7-46ED-433D-B127-4703B1410BDB/148613/OM_ ADR_audienciaweb.pdf.

10 Art. 47.

11 Art. 6.

12 Art. 19. 
Con todo, es preciso un mayor acercamiento y cooperación entre las entidades RAL y los sistemas judiciales, en la medida en que el crecimiento de las entidades RAL puede llegar a comportar un menor uso de los órganos jurisdiccionales, con la consecuente merma de los derechos de los consumidores ${ }^{13}$. Es necesario desarrollar vías de actuaciones conjuntas y coordinadas entre los diferentes mecanismos de resolución de controversias en el ámbito del Derecho de consumo, especialmente para dar satisfacción a las necesidades de las reclamaciones transfronterizas. De ahí que deba ser bien saludado el Anteproyecto de Ley de impulso a la mediación aprobada el pasado 11 de enero por el Consejo de Ministros $-\mathrm{y}$ publicada en sede electrónica el 16 de enero de 2019- ${ }^{14}$ (Anteproyecto de Ley). El objetivo de este Anteproyecto de Ley es la articulación de fórmulas abiertas y flexibles que contribuyan decididamente a implantar la mediación como institución complementaria de la Administración de Justicia y a incrementar su difusión y presencia en el desenvolvimiento ordinario de las relaciones jurídicas entre particulares. Una nueva iniciativa legislativa con la que se pretende potenciar la cultura de la mediación en nuestro país. De hecho, se postula decididamente a favor de un cambio de modelo en este ámbito. Así, del modelo de «mediación voluntaria» adoptado ex art. 6 Ley 5/2012, de 6 de julio, de mediación en asuntos civiles y mercantiles (Ley 5/2012) ${ }^{15}$, se pretende transitar a un sistema de «mediación obligatoria mitigada».

5. Nuestro estudio se ocupará de analizar estas dos propuestas legislativas presentadas por el legislador español y, en concreto, de averiguar en qué medida pueden afectar a la resolución de litigios internacionales de consumo con carácter general, y a las reclamaciones internacionales en el sector del transporte aéreo, en particular. A tales efectos, analizaremos el régimen de la resolución extrajudicial de conflictos de consumo en el ámbito del transporte aéreo propuesto en la citada Propuesta de Orden, y para ello, identificaremos en primer lugar las bases sobre las que se pretende asentar el futuro régimen de resolución extrajudicial de conflictos en este ámbito. Luego pasaremos a analizar si la propuesta legislativa presentada es compatible o no con las exigencias derivadas de la Ley 7/2017, realizando las

13 Aunque la DRAL haya introducido elementos de protección para compensar la pérdida de la vía judicial (ex arts. 9 a 11), los estándares de calidad previstos en el Derecho europeo no son suficientes para garantizar el cumplimiento efectivo del derecho a una tutela judicial efectiva. Además, se han detectado una serie de escollos que no impiden, pero que pueden comprometer el cumplimiento efectivo de dicho principio al generar obstáculos desproporcionados para el acceso a la acción judicial (MARCHAL Escalona, N., op. cit., nota 7, p. 533).

14 https://www.aeafa.es/files/noticias/anteproyectoleyimpulsomediaciOn.pdf.

15 BOE núm. 162, de 7 de julio de 2012. Sobre la transposición de la Directiva 2008/52/CE, del Parlamento Europeo y del Consejo, de 21 de mayo, sobre ciertos aspectos de la mediación en asuntos civiles y mercantiles (DO L núm. 136/3, de 24 de mayo de 2008), véase Civil and Commercial Mediation in Europe, en Iglesias Buhigues, J. L., Esplugues Mota, C. y Palao Moreno, G. (eds.), vol. I, Cambrige, Intersentia, 2013; Civil and Commercial Mediation in Europe, en Iglesias BuHigues, J. L., EsPlugues Mota, C. y Palao Moreno, G. (eds.), vol. II, Cambridge, Intersentia, 2014; Esplugues Mota, C., "General Report: New developments in Civil and Commercial Mediation-Global Comparative Perspectives», en Esplugues Mota, C. y Marquis, L. (eds.), New Developments in Civil and Commercial Mediation Global and Comparative Perspectives, Springer, Heidelberg, 2015. 
propuestas de lege ferenda que resulten precisas. Por último, valoraremos si el nuevo modelo de "mediación obligatoria mitigada» que se pretende instaurar de forma generalizada en nuestro país puede llegar a afectar al tratamiento de las reclamaciones internacionales de consumo, y de ser así, verificar si el modelo propuesto responde a las más elementales exigencias de justicia.

\section{LAS RECLAMACIONES EN EL SECTOR DEL TRANSPORTE AÉREO: LAS LÍNEAS BÁSICAS ESTABLECIDAS EN LA LEY 7/2017}

6. La Ley 7/2017 responde, como ha apuntado la doctrina más autorizada, a las exigencias derivadas de la DRAL ${ }^{16}$. Aunque, como hemos señalado, el sistema español de resolución alternativa de litigios de consumo está por construir. De hecho, la DA 2. ${ }^{a}$ (apdo. 2) de la misma establece que el procedimiento de resolución alternativa de litigios en el ámbito del transporte aéreo será desarrollado a través de una Orden de la persona titular del Ministerio de Fomento.

Según dicha disposición, será solo una la entidad acreditada para la resolución de litigios de consumo en el ámbito del trasporte aéreo y la candidata para ejercer tales competencias será la Agencia Estatal de Seguridad Aérea (AESA $)^{17}$, siempre que dicha entidad acomode su funcionamiento y procedimiento a lo previsto en la Ley 7/2017. No obstante, la actividad de dicha entidad, según dicha ley, parece ser compatible con las Juntas Arbitrales de Consumo y en general todas aquellas entidades que den cobertura a reclamaciones de todos los sectores económicos. Contempla además que el procedimiento de resolución de controversias que deberá configurarse será de aceptación obligatoria y resultado vinculante para las compañías aéreas. Cosa distinta es saber si dicha opción legislativa garantiza que no queda cerrada la vía judicial, es decir, hasta qué punto resulta compatible o no con el derecho a una tutela judicial efectiva. Una cuestión que dependerá, en definitiva, de cómo se configure dicho procedimiento.

16 Esteban DE LA Rosa, F., «El sistema español de resolución alternativa de litigios de consumo y la nueva Ley 7/2017, de 2 de noviembre», en Esteban DE LA Rosa, F. (dir.) y OlARIU, O. (coord.), La resolución de conflictos de consumo. La adaptación del Derecho español al marco europeo de resolución alternativa $(A D R)$ y en Línea (ODR), Navarra, Thomson Reuters-Aranzadi, 2018, pp. 81-105, esp. pp. 81-85.

17 Dicho organismo fue designado para velar en España por el cumplimiento efectivo del Reglamento núm. 261/2004, del Parlamento Europeo y del Consejo, de 11 de febrero, por el que se establecen normas comunes sobre compensación y asistencia a los pasajeros aéreos en caso de denegación de embarque y de cancelación o gran retraso de los vuelos, y se deroga el Reglamento (CEE) núm. 295/91 (DO L núm. 46, de 17 de febrero de 2004). Sobre su funcionamiento, véase https://www.seguridadaerea. gob.es/lang_castellano/particulares/cancelac_retraso/default.aspx. 


\section{ANÁLISIS DE LA NUEVA INICIATIVA LEGISLATIVA SOBRE RESOLUCIÓN ALTERNATIVA DE CONSUMO EN EL ÁMBITO DEL TRANSPORTE AÉREO}

\section{1. Ámbito de aplicación}

7. Para que el consumidor alcance una protección adecuada y efectiva en el ámbito del trasporte aéreo, es preciso que se dé un tratamiento adecuado de las reclamaciones presentadas por los usuarios ${ }^{18}$. No son pocos los casos en los que, pese a la presentación por el consumidor de la pertinente reclamación, la compañía transportista deniega al pasajero la compensación solicitada, o lo que es más gravé, simplemente ignora su reclamación ${ }^{19}$. No sorprende, por tanto, que desde instancias europeas se planteen iniciativas de distinto alcance dirigidas a fomentar la utilización de mecanismos extrajudiciales de resolución de controversias. Aunque, hasta el momento, estas han resultado infructuosas ${ }^{20}$.

De ahí que las esperanzas estén puestas en la Propuesta de Orden proyectada por el Ministerio de Fomento. Según dicha Propuesta, la única entidad acreditada con competencia para resolver los litigios surgidos en el ámbito del transporte será, en sintonía con lo establecido en la Ley 7/2017, la AESA ${ }^{21}$. Aunque, paradójicamente, dicha Propuesta también permite recurrir a otros mecanismos de resolución de conflictos. De hecho, el art. 5 de la P.Or permite al consumidor acudir tanto a la vía judicial como a cualquier sistema extrajudicial de resolución de conflictos aceptado por la compañía aérea o el gestor aeroportuario. El problema que se plantea es que en dicha Propuesta no se definen del todo las relaciones existentes entre tales sistemas. Se trata de una cuestión que, a nuestro juicio, debería haber sido resuelta en la normativa propuesta para evitar problemas prácticos. En concreto, esta debería concretar cómo tendría que actuar la AESA cuando una Junta Arbitral de Consumo estuviere conociendo de una reclamación o, al contrario, qué debería hacer aquella si ya lo está haciendo esta.

8. El ámbito de aplicación de la normativa proyectada se entiende mejor si se tiene en cuenta que el objetivo fundamental de la misma es establecer un mecanismo de resolución de controversias para aquellos conflictos derivados de la aplicación de ciertos Reglamentos aprobados en la Unión Europea para la protección de los usuarios del transporte (art. 1 P.Or). En

18 Sobre la actualidad del tema, véase al respecto la Sentencia del Tribunal de Justicia de la Unión Europea (Sala 6. ${ }^{\text {) }}$ ) de 11 de abril de 2019 (asunto C- 464/18, ECLI:EU:C:2019:311).

19 Rueda VAldivia, R., "Acciones de compensación frente a transportista de hecho por denegación de embarque, cancelación o gran retraso en vuelos de conexión: Aspectos jurisdiccionales», La Ley. Unión Europea, 2018, núm. 59, p. 7.

20 PÉrez Moriones, A., "Hacia la consolidación de la resolución alternativa de conflictos en el ámbito del transporte aéreo», La Ley, 2018, núm. 9.298, pp. 1-14, esp. pp. 2-6.

${ }_{21}$ Será el titular del Ministerio de Fomento la autoridad acreditante de dicha entidad (art. 26.4 Ley 7/2017). 
concreto, dicho procedimiento resultará de aplicación solo a aquellos conflictos nacionales o transfronterizos que se deriven de la aplicación de los Reglamentos (CE) núm. 261/2004 ${ }^{22}$ y núm. 1107/2006 ${ }^{23}$ (art. 3.1 P.Or) ${ }^{24}$. En particular, será aplicable cuando los pasajeros o usuarios afectados -es decir, a toda persona física que actúe con fines ajenos a su actividad comercial, empresarial, oficio o profesión [art. 2.1.a) P.Or] — partan, utilicen o pretendan utilizar vuelos que salgan de un aeropuerto situado en territorio español o que partan de un país que no sea miembro de la UE con destino a otro situado en territorio español, siempre que la empresa operadora sea comunitaria $^{25}$ y el gestor aeroportuario esté situado en territorio español. Dos precisiones hay que hacer al respecto. En primer lugar, evidenciar que la Propuesta de Orden eleva el nivel de protección del consumidor/usuario al extender su ámbito de aplicación del Derecho europeo a aquellos supuestos en los que consumidores no residen en la UE. Y, en segundo lugar, precisar que la perspectiva acogida por esta iniciativa legislativa para delimitar su ámbito de aplicación espacial no responde al criterio establecido en la DRAL (art. 2 DRAL) ${ }^{26}$-y corroborado por el TJUE en la Sentencia de 14 de mayo de 2017 (asunto C-75/16) 27 _. Según el cual, la DRAL resulta de aplicación indistintamente a los litigios nacionales y transfronterizos relativos a las obligaciones contractuales derivadas de contratos de compraventa o de prestación de servicios entre un comerciante establecido en la UE y un consumidor residente en la Unión. No obstante, la perspectiva unilateralista adoptada por el legislador español en la presente iniciativa legislativa impide que la AESA tenga competencia para conocer de todas las reclamaciones

22 Del Parlamento Europeo y del Consejo, de 11 de febrero de 2004, por el que se establecen normas comunes sobre compensación y asistencia a los pasajeros aéreos en caso de denegación de embarque y de cancelación o gran retraso de los vuelos, y se deroga el Reglamento (CEE) núm. 295/91 (DO L núm. 46, de 17 de febrero de 2004).

23 Del Parlamento Europeo y del Consejo, de 5 de julio de 2006, sobre los derechos de las personas con discapacidad o movilidad reducida en el transporte aéreo (DO L núm. 204, de 26 de julio de 2006).

${ }^{24}$ En concreto, dicho precepto dispone que: «Esta orden es de aplicación al procedimiento [...] para la resolución de los conflictos, nacionales o transfronterizos, que surjan respecto de la aplicación de: a) el Reglamento (CE) núm. 261/2004, del Parlamento Europeo y del Consejo, de 11 de febrero de 2004, cuando: 1. Los pasajeros partan de un aeropuerto situado en territorio español, o 2. Los pasajeros partan de un aeropuerto situado en un país que no sea miembro de la Unión Europea, con destino a otro situado en territorio español, a menos que disfruten de beneficios o compensación y de asistencia en ese país no perteneciente a la Unión Europea, cuando la compañía aérea operadora sea una compañía aérea comunitaria; b) el Reglamento (CE) núm. 1107/2006, del Parlamento Europeo y del Consejo, de 5 de julio de 2006, cuando: 1. Las personas con discapacidad o movilidad reducida utilicen o pretendan utilizar vuelos comerciales de pasajeros que salgan de los aeropuertos situados en territorio español, lleguen a estos aeropuertos o transiten por ellos».

25 Es decir, siempre que posea una licencia de explotación válida expedida por un Estado miembro de conformidad con las disposiciones del Reglamento (CEE) núm. 2407/92, del Consejo, de 23 de julio, sobre la concesión de licencias a las compañías aéreas (DO L núm. 240, de 24 de agosto de 1992).

${ }^{26}$ Sobre el mismo, véase Esteban DE LA Rosa, F., «El régimen de Derecho internacional privado de la resolución alternativa de litigios de consumo en la directiva 2013/11/UE y la Ley 7/2017», en ESTEBAN DE la Rosa, F. (dir.) y Olariu, O. (coord.), La resolución de conflictos de consumo. La adaptación del Derecho español al marco europeo de resolución alternativa (ADR) y en Línea (ODR), Navarra, Thomson Reuters-Aranzadi, 2018, pp. 415-442, esp. pp. 417-420.

27 Considerando 40, ECLI:EU:C:2017:457. 
surgidas entre consumidores con residencia habitual en la Unión Europea frente a empresarios establecidos en un Estado miembro. Cabe afirmar, por tanto, que dicha regulación no se compadece bien ni con el Derecho europeo ni con el ámbito de aplicación espacial de la Ley 7/2017. Por ello, desde aquí, de lege ferenda, consideramos que sería preciso modificar el ámbito de aplicación de dicha Propuesta legislativa, para que la AESA pudiera conocer de aquellos litigios transfronterizos tal y como son definidos por el propio Derecho europeo, es decir, aquellos en los que el consumidor reside en un Estado miembro de la Unión Europea frente a un empresario establecido en otro Estado.

Además, sería también necesario que el legislador español aclarara si los litigios de los que derivan tales reclamaciones pueden haber surgido en línea o no, puesto que, a pesar de existir una disposición que hace referencia a ello (art. 9.5 P.Or), no resulta evidente.

9. Dicha Propuesta delimita asimismo su ámbito de aplicación desde una perspectiva subjetiva y material. Esta solo se aplica a los procedimientos iniciados por los usuarios/pasajeros frente al empresario. De hecho, el concepto de pasajero/usuario que emplea la P.Or (art. 2.1) es más restringido que el concepto de consumidor que establece la Ley 7/2017, que incorpora además a las personas jurídicas ${ }^{28}$. Aunque dicha limitación tiene su lógica al ajustarlo al ámbito de la actividad que regula: el transporte aéreo, dicho concepto debería de haber sido amoldado para tener en cuenta las previsiones existentes en la Directiva 2015/2302/UE, de 25 de noviembre, relativa a los viajes combinados y a los servicios de viajes vinculados ${ }^{29}$, que extiende la protección de la que disfruta el consumidor en materia de viajes combinados al representante de una pequeña empresa o al profesional, siempre que este último no se sirva de un convenio general para la gestión u organización de sus viajes (considerando 7) ${ }^{30}$.

De manera similar, el procedimiento que diseña el legislador español no comprende todas las reclamaciones que el usuario puede plantear en este ámbito. En concreto, el art. 4 de la iniciativa propuesta enumera aquellos aspectos que están excluidos del ámbito de aplicación material. Así, excluye cualquier litigio relativo a los daños y perjuicios causados por el incumplimiento o cumplimiento defectuoso del contrato de transporte y las reclamaciones de los usuarios en base al Reglamento (CE) núm. 2027/97, del Consejo, de 9 de octubre, relativo a la responsabilidad de las compañías aéreas respecto al transporte aéreo de los pasajeros y su equipaje, o las reclamaciones por la destrucción, pérdida, avería o retraso de los equipajes facturados en base a cualquier otra norma o convención [art. 4.a) y e) ${ }^{31}$. A nuestro juicio, dicha exclusión resulta incomprensible, puesto que afecta a un número importante

\footnotetext{
28 Sobre el mismo, véase Esteban DE LA Rosa, F., op. cit. nota 16, pp. 90-91.

29 DO L núm. 326/1, de 11 de diciembre de 2015.

30 En este sentido, véase Pérez Moriones, A., op. cit., nota 20, p. 7.

31 DO L núm. 285, de 17 de octubre de 1997.
} 
de reclamaciones ${ }^{32}$. Es cierto que la AESA surge para conocer de las reclamaciones relacionadas con el incumplimiento de las obligaciones establecidas en el Reglamento núm. 2006/2004, pero también lo es que en esta iniciativa legislativa se le confiere a aquella la potestad para conocer de aquellos litigios que surjan como consecuencia de la inobservancia del Reglamento (CE) núm. 1107/2006. Entonces, ¿por qué no conferirle también a la AESA la competencia para conocer de los litigios derivados del incumplimiento del Reglamento (CE) núm. 2027/97? Una cuestión que alcanza todo su sentido, máxime teniendo en cuenta que dicho Reglamento forma parte del acervo comunitario en materia de derechos de los pasajeros. Por ello, animamos a que, de lege ferenda, sean incluidos en el ámbito de aplicación de dicha propuesta normativa aquellos aspectos relativos al daño causado por el transporte aéreo de los pasajeros y su equipaje, así como las reclamaciones por la destrucción, pérdida, avería o retraso de los equipajes facturados.

Quedan excluidos además del ámbito de aplicación de la Propuesta de Orden aquellos litigios que afecten a las cláusulas y prácticas abusivas en el contrato de transporte aéreo u otra documentación atinente al transporte, las prácticas desleales, publicidad o información precontractual o contractual, la protección de datos de carácter personal, así como las previstas en el art. 3.2 Ley $7 / 2017$ [art. 4.b), c) y f)].

\subsection{El procedimiento de resolución de controversias en el ámbito del transporte aéreo}

10. Con carácter previo a la iniciación del procedimiento diseñado en la proyectada Orden, y en sintonía con lo previsto en el art. 18 Ley 7/2017, el consumidor deberá haber planteado su pretensión ante el responsable del incumplimiento que origina la reclamación, aportando la documentación que considere pertinente para hacer valer sus derechos (art. 7 P.Or). Cuando esta no haya sido resuelta en el plazo de un mes o no sea totalmente satisfactoria, la compañía aérea o el gestor aeroportuario deberán informar al consumidor si se encuentran adheridos a una entidad de resolución alternativa de litigios de consumo en España o en cualquier Estado miembro de la Unión Europea (ex art. 40 Ley 7/2017) y, en todo caso, de la posibilidad de presentar su reclamación ante la AESA (art. 6 P.Or). De hecho, consideramos que las propias compañías aéreas deberían también de informar a los consumidores que están obligadas a participar en este procedimiento ante la AESA.

11. El procedimiento a seguir está regulado en el Capítulo II de la Propuesta de Orden. Este se inicia con la presentación de la oportuna reclamación ante la AESA bien a través de su sede electrónica o en papel (art. 9.1 P.Or), aunque tampoco hay que olvidar que también se puede presentar a través de la Plataforma ODR (art. 9.5 P.Or).

32 Pérez Moriones, A., op. cit., nota 20, p. 8. 
En concreto, dicha reclamación se realizará en el formulario que al efecto adopte la AESA y al que se podrá acceder a través de su página web (art. 9 y DA 2. ${ }^{a}$ P.Or $\left.{ }^{33}\right)$.

La reclamación deberá presentarse ante la AESA. Aunque, a nuestro juicio, en la práctica el mayor problema para el consumidor será determinar cuál es la autoridad o entidad RAL competente para la resolución de una controversia surgida en el ámbito del transporte aéreo. Y ello porque, por una parte, las empresas responsables pueden estar obligadas a participar ante una determinada entidad RAL o adheridas a una o varias entidades RAL. Y, por otra, porque cada Estado ha designado a organismos estatales con competencia para garantizar el cumplimiento de lo establecido en el Reglamento (CE) núm. 261/2004, aunque hay que reconocer que, salvo excepciones, tales organismos carecen de competencia para la resolución de reclamaciones individuales de pasajeros ${ }^{34}$. Este problema se agrava, como hemos tenido oportunidad de analizar, porque la Propuesta proyectada no ha delimitado su ámbito de aplicación espacial de acuerdo con lo que dicta el Derecho europeo. De haberlo hecho así, la AESA tendría competencia para conocer de todo litigio surgido entre consumidores residentes en la UE frente a empresas establecidas en un Estado miembro.

$\mathrm{Al}$ no hacerlo, y siendo el legislador español consciente de este problema, la Propuesta de Orden contempla que, en caso de que la competencia para conocer de la reclamación corresponda a otro Estado miembro, la AESA tiene la obligación de trasladar dicha reclamación a la entidad de resolución alternativa de litigios que aquel Estado hubiera notificado a tales efectos, al Centro Europeo del Consumidor en España ${ }^{35}$, si hubiera notificado varias entidades que resulten competentes, o al organismo responsable del cumplimiento del Reglamento (CE) núm. 261/2004 o del Reglamento (CE) núm. 1107/2006, o a ambos según corresponda (art. 12). Es cierto que esta previsión puede contribuir de forma muy positiva para identificar la entidad RAL competente para resolver el conflicto. Y es que una adecuada protección del consumidor requiere que este reciba información no solo de sus derechos, sino también sobre cómo tramitar sus reclamaciones y frente a quién hacerlo ${ }^{36}$. De hecho, esta es, a nuestro juicio, la asignatura pendiente a resolver en este ámbito. Por lo que deberían fomentarse y explotarse todos los medios de los que se

33 La AESA deberá incluir en el formulario que debe elaborar un contenido mínimo (ex art. 9.2 de la P.Or), además, de la información a la que se refiere el art. 14.1 Ley 7/2017, con miras a que el consumidor tenga conocimiento de las garantías establecidas por el Derecho europeo antes de la presentación de la reclamación.

34 Rueda Valdivia, R., op. cit., nota 19, p. 7.

35 Sobre las funciones asumidas por este, véase PAREDES PÉREZ, J. I., «La participación del centro europeo del consumidor en España en la resolución de litigios transfronterizos de consumo: ¿cambio de funciones? o ¿nuevas funciones?», en EsTEBAN DE LA ROSA, F. (dir.) y OlaRIU, O. (coord.), La resolución de conflictos de consumo. La adaptación del Derecho español al marco europeo de resolución alternativa (ADR) y en Línea (ODR), Navarra, Thomson Reuters-Aranzadi, 2018, pp. 395-413.

36 Sobre la importancia del principio de información en este ámbito, véase MARCHAL EsCALONA, N., op. cit., nota 2, pp. 1015-1051. 
dispone en tal sentido. Justamente la propia Plataforma europea ODR podría servir a tales propósitos ${ }^{37}$.

12. Dicha reclamación solo podrá ser inadmitida a trámite si concurre cualquiera de las causas previstas en el art. 7 de la Propuesta de Orden, un precepto que eleva, como lo hace el art. 18 Ley 7/2017, la protección del consumidor frente a lo dispuesto en el art. 5.4 DRAL ${ }^{38}$. En el caso de que sea admitida, se dará audiencia a la compañía aérea o gestor aeroportuario reclamado, trasladándole la reclamación y documentación presentada por el consumidor y dándole un plazo de veinte días hábiles para que formule las observaciones y proponga o presente las pruebas que considere pertinentes para hacer valer su derecho ${ }^{39}$. En otro caso, se dará audiencia al consumidor por un plazo de diez días hábiles al objeto de que formule las alegaciones o presente los documentos que estime pertinentes, y proponga otros medios de prueba de los que intente valerse, teniéndole por decaído en el trámite en el caso de que no le dé cumplimiento en el plazo indicado (art. 16.2 P.Or).

13. Mención especial merece la posibilidad que ofrece el art. 15.1 de la Propuesta de Orden de acordar, de oficio o a instancia de parte, la acumulación de los procedimientos que guarden identidad sustancial o íntima conexión, es decir, de aquellas reclamaciones que traigan causa en los mismos hechos. Una regla de acumulación de acciones que debe ser valorada en sentido positivo, pues resulta eficiente en términos de análisis económico del Derecho. Además, dicho precepto admite también que en los procedimientos no acumulados que tengan su causa en los mismos hechos la AESA posee la facultad de incorporar al respectivo proceso las alegaciones y documentación presentada por la compañía aérea o el gestor aeroportuario formuladas en otros procedimientos para así determinar si concurren las circunstancias determinantes de la aplicación de los Reglamentos de la Unión Europea (art. 15.2 P.Or). Una previsión que merece igualmente una valoración positiva, pues permite dictar resoluciones participadas por el principio de coherencia.

14. La AESA deberá resolver sobre la práctica de las pruebas propuestas por las partes, pudiendo acordar de oficio la práctica de las pruebas complementarias que considere imprescindibles para la solución de la controversia.

\footnotetext{
37 Sería de interés que la Plataforma Europea ODR incorporase una funcionalidad a fin de permitir conocer si las empresas responsables se encuentran adheridas u obligadas a participar ante alguna entidad RAL [MARqués CEBola, C., «La resolución en línea de litigios de consumo en la nueva plataforma europea ODR. Perspectiva desde los sistemas español y portugués», en EsTEBAN DE LA RosA, F. (dir.) y OLARIU, O. (coord.), La resolución de conflictos de consumo. La adaptación del Derecho español al marco europeo de resolución alternativa (ADR) y en Línea (ODR), Navarra, Thomson Reuters-Aranzadi, 2018, pp. 374-375].

38 En el caso de que la AESA no admita la reclamación presentada, su resolución deberá ser notificada al usuario dentro de los veintiún días naturales desde la recepción de la reclamación (art. 11.2 P.Or). Contra la misma se podrá interponer recurso potestativo de reposición. En cualquier caso, la presentación de la reclamación ante la AESA suspenderá o interrumpirá los plazos de caducidad y prescripción de acciones que sean aplicables (art. 13 P.Or).

39 Transcurrido el plazo previsto sin que la compañía aérea o gestor aeroportuario reclamado haya formulado observaciones, se le tendrá por desistido del respectivo trámite, prosiguiéndose la tramitación del procedimiento, pudiendo prescindirse del trámite de audiencia del interesado (art. 16.1 P.Or).
} 
Ahora bien, es de reseñar que los gastos ocasionados por las pruebas practicadas a instancia de parte serán sufragados por quien las haya propuesto y las comunes o coincidentes por mitad (art. 17 P.Or). Practicadas las pruebas admitidas, se dará nueva audiencia a las partes por un plazo improrrogable de diez días hábiles, si fuera necesario para garantizar la igualdad y contradicción de las partes en el procedimiento, y, a continuación, resolverá la AESA y determinará las medidas a adoptar (art. 18.1 P.Or). El plazo para dictar esta resolución será de noventa días naturales contados desde la fecha de la presentación de la reclamación o, en su caso, desde la fecha en que conste en soporte duradero que se ha recibido la documentación completa y necesaria para tramitar el procedimiento (art. 18.2 P.Or), prorrogables cuando concurra especial complejidad en la controversia, o cuando no existan o se hayan agotado los medios personales y materiales disponibles ${ }^{40}$. Transcurrido dicho plazo sin que se haya dictado resolución, el consumidor podrá entender desestimada su reclamación por silencio administrativo (art. 18.4 P.Or) ${ }^{41}$.

\subsection{La adaptación de la iniciativa proyectada al marco estatal de resolución alternativa de litigios de consumo}

15. El procedimiento de resolución de controversias descrito y regulado en la Propuesta de Orden responde, según establece su art. 8, a los principios de independencia, imparcialidad, transparencia, eficacia y equidad establecidos en la Ley 7/2017. A continuación nos ocuparemos de analizar hasta qué punto la iniciativa proyectada responde a tales exigencias.

\subsubsection{Principios de independencia, imparcialidad y eficacia}

16. La financiación pública de la que dispone la AESA facilita el cumplimiento del principio de independencia e imparcialidad que los arts. 23 a 25 Ley 7/2017 (art. 6 DRAL) establecen. Tampoco cabe dudar del cumplimiento de las condiciones y cualificación que se exigen a las personas encargadas de la resolución de los procedimientos ex art. 22 Ley 7/2017 (art. 6 DRAL), puesto que la competencia para resolver de los litigios surgidos en este ámbito corresponde a la AESA, a través de su director/a (art. 19.1 y art. 3.1 P.Or), por lo que debe presuponerse que tal/es persona/s cuenta/n con conocimientos

40 Dicha prórroga no podrá ser superior al plazo de noventa días naturales previsto para la resolución.

41 Dicha resolución será vinculante e inmediatamente ejecutiva para la compañía aérea que deberá hacerla efectiva en un plazo máximo de un mes desde la notificación de la resolución, acreditando tal circunstancia ante la Agencia. En caso de que la compañía aérea no acredite en plazo el cumplimiento de la resolución, la Agencia podrá iniciar de oficio un procedimiento administrativo sancionador, para la protección de los derechos de los usuarios del transporte aéreo (art. 18.5 P.Or). Las resoluciones dictadas por el director de la Agencia ponen fin a la vía administrativa y frente a ellas solo cabrá el recurso ante la jurisdicción contencioso-administrativa, sin perjuicio de la posibilidad de interponer el potestativo de reposición. 
necesarios y una metodología de actuación suficientes para hacer un análisis jurídico de la situación litigiosa y aplicar correctamente las normas. Por el contrario, no podemos entrar a valorar si la iniciativa presentada cumple o no con las exigencias derivadas del principio de imparcialidad, puesto que nada se especifica en ella. Quizá, porque esta cuestión debe estar prevista y regulada en el Estatuto de la Agencia, que entendemos que deberá ser modificado para que la AESA pueda ser acreditada (ex art. 29 Ley 7/2017). De hecho, la existencia de dicho Estatuto nos permite concluir el cumplimiento del principio de transparencia, siempre que sean observadas las exigencias contenidas en el art. 35 Ley 7/2017. Eso sí, para cumplir con la segunda vertiente de este principio (que obliga a ofrecer información sobre el número de litigios recibido, tipos de reclamaciones, problemas sistemáticos, etc.), la AESA deberá contar con medios personales y materiales suficientes. Es ahí donde radica, en nuestra opinión, el mayor problema, dado que en la DA $1 .^{\text {a }}$ de esta iniciativa legislativa establece que las medidas incorporadas en esta normativa no suponen, en modo alguno, incremento de las asignaciones presupuestarias, ni de dotaciones o retribuciones u otros gastos de personal. Una decisión de política legislativa que comprometerá, sin duda alguna, la eficacia y efectividad de dicho procedimiento.

17. Tampoco existen mayores problemas para determinar la compatibilidad del régimen de la Propuesta de Orden respecto de las exigencias que se derivan del principio de eficacia (arts. 17, 10, 11 y 20 Ley 7/2017). Y es que el procedimiento no solo se proyecta como accesible tanto en línea como en papel (art. 9 P.Or), sino que obliga también a las partes sean informadas de que no están obligadas a actuar asistidas por el abogado o asesor jurídico (art. 14.1 P.Or) ${ }^{42}$. Además, dicho proceso tiene carácter gratuito o un coste no muy elevado, puesto que las partes están obligadas a cubrir los costos derivados de las pruebas (art. 17.2 P.Or) en sintonía con lo establecido en la Ley 7/2017 (art. 7.1 DRAL). Por otra parte, la plena compatibilidad del procedimiento diseñado con la Ley 7/2017 tiene que ver con el plazo máximo para la obtención de una solución al litigio. El principio de eficacia obliga a que el resultado del proceso ante la entidad RAL acreditada se dé a conocer en un plazo de noventa días, plazo que puede ampliarse ante litigios de índole compleja, como así ha establecido la iniciativa proyectada (art. 18.3 P.Or). De forma que, transcurrido el plazo previsto en el apartado anterior sin que se haya dictado resolución, el usuario podrá entender desestimada su reclamación por silencio administrativo (art. 18.4 P.Or.). Es evidente que el cumplimiento efectivo de dicho principio dependerá de la suficiencia de medios y personal con la que se dote a la AESA. Difícilmente se podrá atender a dicho principio si no se le dota a dicha entidad de más recursos humanos, como así establece la DA $1{ }^{a}{ }^{\mathrm{P}} \mathrm{P} . \mathrm{Or}^{43}$.

\footnotetext{
42 Ello, sin perjuicio del derecho que tienen las partes de acceder al procedimiento en cualquiera de sus fases pudiendo comparecer por sí mismas, representadas o asistidas por tercero, y solicitar, si así lo desean, asesoramiento independiente (art. 14.2 P.Or).

43 Véase García Montoro, L., "Las medidas incluidas en la norma no supondrán incremento de dotaciones ni de retribuciones ni otros gastos de personal. A propósito de la disposición adicional
} 


\subsubsection{Principios de equidad, libertad y legalidad}

18. La coordinación entre el procedimiento de resolución de controversias establecido en la Propuesta de Orden y las exigencias que derivan del principio de equidad (arts. 17 y 10 Ley 7/2017) es manifiesta al establecer aquella las exigencias relacionadas con el principio de contradicción (art. 16 P.Or) y representación (art. 14 P.Or), además de obligar a informar a las partes de que no están obligadas a ser asistidas por letrado, aunque pueden solicitar asesoramiento o estar representadas o asistidas en cualquier fase del proceso. El art. 9.3 P.Or satisface parcialmente las exigencias que provienen de este principio, al limitar la información que la AESA deberá incorporar en el formulario que debe adoptar solo a los extremos previstos en el art. 14.1 Ley 7/2017. Sin embargo, no contiene la obligación de informar al consumidor de que antes de dar su consentimiento a una solución propuesta, debe disponer de un plazo de reflexión no inferior a tres días hábiles a contar desde la recepción de la propuesta. Esta carencia debería ser subsanada para compatibilizar esta normativa con la Ley 7/2017. Es más, creemos necesario que dicha información sea facilitada al consumidor en un idioma comprensible para este, pues de lo contrario puede estar haciendo una renuncia inopinada a la vía judicial. El «idioma» puede constituir uno de los mayores obstáculos para garantizar el acceso a una tutela judicial efectiva en los supuestos transfronterizos en este ámbito ${ }^{44}$. Lamentablemente, esta cuestión no ha sido expresamente prevista ni regulada ni en la DRAL ni en la Ley 7/217 ni en la P.Or.

19. En cuanto al principio de libertad, el art. 15 Ley 7/2017 contempla situaciones en las que no se requiere la acepción ad hoc del empresario para el inicio del procedimiento ante una entidad RAL, lo que sucede cuando la empresa está obligada a participar en el procedimiento ante una entidad RAL, como sucede en el proceso diseñado ante la AESA (art. 8 P.Or). En tales casos, y según lo preceptuado en el art. 9.2 Ley 7/2017, no debe excluirse el acceso a la vía judicial. A nuestro juicio, el procedimiento diseñado en la iniciativa proyectada no la excluye, en la medida en que admite que pueda recurrirse la decisión vinculante que se dicte. Por lo que cabe afirmar que queda garantizado el derecho fundamental de acceso a la jurisdicción.

Con todo, lo que esta iniciativa legislativa parece no tener claro es la diferencia que existe entre el carácter que tiene el procedimiento ante la AESA y el que debe revestir la decisión que se adopte en el mismo. Y ello, porque del tenor literal del art. 6 de la P.Or cabe deducir que el procedimiento ante la AESA es de naturaleza obligatoria tanto para el gestor aeroportuario como

\footnotetext{
tercera del Anteproyecto de Ley de Resolución Alternativa de Conflictos de Consumo», CESCO, 3 de junio de 2015.

${ }_{44}$ Marchal Escalona, N., op. cit., nota 6, pp. 511-524; Palao Moreno, G., «Cross-border Consumer Redress after the ADR Directive and the ODR Regulation», en CoRTÉs, P. (ed.), The New Regulatory framework for consumer dispute resolution, Oxford, Oxford University Press, 2016, pp. 393-405, esp. p. 400.
} 
para la compañía aérea. No obstante, el art. 8.2.b) de la misma Propuesta estipula que dicho procedimiento es para los usuarios y los gestores aeroportuarios de aceptación voluntaria y resultado no vinculante; mientras que de aceptación obligatoria y resultado vinculante para las compañías aéreas [art. 8.2.c) P.Or]. Ese extremo resulta confuso y debe ser aclarado. A nuestro juicio, la intención del legislador era configurar un procedimiento de naturaleza obligatoria tanto para las compañías aéreas como para el gestor aeroportuario, pero con resultado vinculante solo para aquellas. Una opción de política legislativa que no compartimos. El procedimiento debería ser, de lege ferenda, de aceptación obligatoria y resultando vinculante tanto para compañías aéreas como para los gestores aeroportuarios. Por lo que la P.Or debería ser modificada en dicho sentido. Pero hay que ser realistas. La modificación propuesta va claramente en contra de los intereses de los gestores aeroportuarios, y hay que tener en cuenta que en España el mayor gestor aeroportuario es AENA, sociedad pública, y esta, como es obvio, hará todo lo que esté en sus manos para evitar que esta se produzca.

En cualquier caso, el problema radica en saber cuál es el alcance que posee dicha obligación legal, es decir, hasta qué punto una compañía aérea o el gestor aeroportuario tiene la obligación legal de participar en dicho proceso. Pues bien, ni la DRAL ni la Ley 7/2017 establece la ley a la que corresponde decidir en torno a la existencia de una eventual obligación legal de adhesión al procedimiento ante una entidad RAL. La DRAL parece apuntar que dicha cuestión depende del lugar donde esté establecida la empresa. Por lo que, según esto, serán las compañías aéreas y los gestores aeroportuarios establecidos en España los que tendrían la obligación legal de someterse al procedimiento ante la AESA. Pero también es cierto que, según Fernando Esteban de la Rosa, la existencia de un volumen importante de actividad de una empresa en un país distinto al de su establecimiento podría proporcionar argumentos para extender sobre tales empresas las mencionadas obligaciones ${ }^{45}$. Por lo que sería muy útil y necesario que la futura normativa se pronunciara al respecto.

20. No obstante, queda por determinar el carácter que reviste la participación del consumidor en este procedimiento. Ni la DRAL ni la Ley 7/2017 establecen la ley a la que corresponde decidir si el consumidor tiene la obligación legal de adhesión al procedimiento ante una entidad de RAL, pero lo que sí es evidente es que si dicha ley obliga al consumidor a participar ante dicha entidad, puede suponer una excepción y un límite importante al derecho a la tutela judicial efectiva, siempre que no se observe lo preceptuado en el Derecho europeo ${ }^{46}$, tal y como ha sido refrendado en las decisiones del TJUE de 18 de marzo de $2010^{47}$ y de 14 de junio de 2017.

45 Id., «El régimen de Derecho internacional privado de la resolución alternativa de litigios de consumo en la Directiva 2013/11/UE y la Ley 7/2017», en ESTEBAN DE LA RosA, F. (dir.) y OLARIU, O. (coord.), La resolución de conflictos de consumo. La adaptación del Derecho español al marco europeo de resolución alternativa (ADR) y en Línea (ODR), Navarra, Thomson Reuters-Aranzadi, 2018, p. 428.

46 Marchal Escalona, N., op. cit., nota 6, pp. 516-520.

47 Asuntos C-317/08, C-318/08, C-319/08 y C-320/08, ECLI:EU:C:2010:146. 
21. Mención especial merece el art. 18.1 de la P.Or, que obliga a la entidad RAL acreditada a garantizar los derechos de los consumidores tal y como son reconocidos desde las propias fuentes europeas, lo cual debe ser valorado positivamente, puesto que a la vista de la dicción del art. 16.1 Ley 7/207 el principio de legalidad que proclama dicha norma solo resulta aplicable cuando la decisión de la entidad RAL posee carácter vinculante. En el resto de los supuestos se parte de la idea de que los derechos de los consumidores están protegidos de forma suficiente.

\section{HACIA LA «MEDIACIÓN OBLIGATORIA MITIGADA» EN EL SISTEMA JURÍDICO ESPAÑOL}

\subsection{Introducción}

22. Cada vez cobra más fuerza entre la doctrina la conveniencia de desarrollar vías de actuación conjuntas y coordinadas entre los diferentes mecanismos de resolución de controversias en el ámbito del Derecho de consumo capaces de satisfacer las necesidades del consumidor transfronterizo ${ }^{48}$. De hecho, desde propias europeas se han barajado propuestas en este sentido. En este contexto, cabe destacar el estudio de Derecho comparado elaborado a iniciativa del Parlamento Europeo sobre la aplicación de la Directiva sobre mediación ${ }^{49}$, en el que se reconoce que, a pesar de los evidentes beneficios que la mediación despliega, este sigue siendo un sistema escasamente utilizado para la resolución de los conflictos ${ }^{50}$. No obstante, es una opción que cuenta con más adeptos y con reflejo en Derecho comparado (sistema jurídico italiano y francés) ${ }^{51}$.

48 Vos, G., "The Relationship between Formal and Informal Justice: the Courts and Alternative Dispute Resolution (ADR)», en The Implementation of the mediation Directive 29 November de 2016, http://www.europarl.europa.eu/supporting-analyses, pp. 31-42. De hecho, en Derecho comparado existen experiencias en este sentido, como así sucede, por ejemplo, con los mediateurs de consumo en Francia, la mediación adjudicativa en Italia, los procesos ante la Oficina Nacional de Reclamaciones de los Consumidores en Suecia o el Financial Ombudsman Service en Reino Unido (Marchal Escalona, N., op. cit., nota 7, pp. 523-524).

49 El resultado de dicho estudio se reflejó en el documento titulado "Rebooting" the mediation Directiva: assessing the limited impact of its implementation and proposing measures to increase the number of mediations in the EU», presentado por la Comisión de Asuntos Jurídicos del Parlamento Europeo en febrero de 2014 en Bruselas (http://www.europarl.europa.eu/studies). Sobre el mismo, AzCÁRRAGA MonzonIS, C., «El (limitado) impacto de la Directiva de mediación y la mediación obligatoria como medida de promoción", en BARONA VILAR, S. (ed.), Mediación, arbitraje y jurisdicción en el actual paradigma de justicia, Pamplona, Aranzadi, 2016; Ginebra Molins, M. E. y TARABAL Bosch, J., «La obligatoriedad de la mediación derivada de la voluntad de las partes: las cláusulas de mediación», Indret, 2013, núm. 4, pp. 1-31.

50 Lo que se ha dado en llamar la "paradoja de la mediación», es decir, la desconexión que existe entre los beneficios de la misma y el uso tan limitado que se hace de ella (PÉrez MorionEs, A., «En torno a la paradoja de la mediación», La Ley, 2014, núm. 8.316, p. 3).

51 De Palo, G. y Canessa, R., «New Trends for ADR in the European Union», en Cortés, P. (ed.), The New Regulatory Framework for Consumer Dispute Resolution, Oxford, Oxford University Press, 2016, p. 418. 
Por ello, debe ser bien saludada la nueva iniciativa legislativa presentada para implantar en nuestro país la mediación como institución complementaria a la Administración de Justicia. A tales efectos, pretende superar el modelo de mediación voluntaria vigente en Derecho español y sustituirlo por el de "obligatoriedad mitigada» ${ }^{52}$. Tales objetivos pretenden materializarse, según anuncia la Exposición de motivos del Anteproyecto de Ley de impulso a la mediación, a través de ciertas medidas de índole procesal ${ }^{53}$, sin olvidar la labor que la concienciación y la formación ${ }^{54}$ puede desempeñar para la efectiva instauración de este sistema de resolución de conflictos en nuestro país ${ }^{55}$.

La regulación propuesta pretende implantar un modelo de mediación obligatoria/voluntariedad «mitigada», capaz de desempeñar un papel fundamental en dos momentos procesales distintos: previamente a la interposición de determinadas demandas - mediación extrajudicial-y durante el proceso -mediación intrajudicial $-{ }^{56}$. Puesto que este último tipo de mediación está excluido del ámbito de aplicación de la DRAL [art. 12.2.f)], nos centraremos en analizar cómo ha diseñado el legislador español la mediación extrajudicial y, en concreto, su funcionamiento y regulación.

23. Pues bien, para instaurar la mediación extrajudicial en España, el Anteproyecto modifica el art. 6.1 Ley 5/2012 para prever la obligación de las partes de llevar a cabo - solo en un número determinado de materias- un intento de mediación con carácter previo al inicio de un proceso. Este consistirá en la celebración ante el mediador de una sesión informativa y una exploratoria que podrán celebrarse en un único acto, y que deberán realizarse dentro de los seis meses anteriores a la presentación de la demanda y a la que tendrán que asistir las partes, bien personalmente, si se trata de personas físicas, bien por medio de representante legal o persona con poder para transigir, si se trata de personas jurídicas.

52 Un modelo que ya había sido propuesto tanto en el Anteproyecto de Ley de mediación de 2010 como el Proyecto de Ley de 2011, además de ser una propuesta reclamada por la judicatura en el Informe de los Presidentes de los Tribunales Superiores de Justicia del año 2009 (PÉREz Moriones, A., «El Anteproyecto de Ley de Impulso de la Mediación: en particular, la regulación de la mediación obligatoria mitigada», Diario La Ley, 2019, núm. 9.360, p. 5).

53 A tales efectos, aborda la reforma desde varios frentes normativos, a saber: la Ley 1/2000, de 7 de enero, de Enjuiciamiento Civil (BOE núm. 7, de 8 de enero de 2000 y posteriores modificaciones), la Ley 5/2012 y la Ley 1/1996, de 10 de enero, de asistencia jurídica gratuita (BOE núm. 11, de 12 de enero de 1996 y posteriores modificaciones).

54 De hecho, en el plazo de un año desde la publicación de la ley se prevé la modificación de los planes formativos del grado en Derecho, así como de otros grados afines para incluir la asignatura de mediación como obligatoria (DA 2. ${ }^{\mathrm{a}}$ ). El Informe presentado por el Consejo General del Poder Judicial (CGPJ) al Anteproyecto de Ley de impulso a la mediación va más allá y establece la oportunidad de extender dicha previsión a ciclos formativos, así como en temarios de oposiciones a cuerpos de la Administración. Disponible en http://mediasviewer.wkcols.com/pdfView.ashx?url_data_id=8905072\&reposi toryType $=$ es\&action $=G E T$, p. 55.

55 Resulta llamativa la previsión de una vacatio legis de tres años (DF 2. a), pues compagina mal con el objetivo de implantar la mediación. Sobre la necesidad de reducir dicho periodo, véase el Informe del CGPJ al Anteproyecto de Ley de impulso a la mediación, cit., nota 58, p. 55.

56 Dicho Anteproyecto contempla también la posibilidad de que el procedimiento de mediación se inicie por decisión judicial. A tales efectos, introduce dos nuevos artículos (398 bis y 398 ter) en la LEC, que conformarán el nuevo Capítulo IX del Título I del Libro II LEC. 
Adopta, así, un modelo similar al establecido en Italia (art. 51 bis del Decreto legislativo de 4 de marzo de 2010 , núm. 28) ${ }^{57}$ y acogido paulatinamente en otros Estados miembros de la Unión Europea ${ }^{58}$, que resulta, en principio, compatible con el principio de voluntariedad, propio de la mediación, puesto que implica únicamente la obligación de las partes de asistir en determinadas materias y procesos a ciertas sesiones dirigidas a informar y explorar tanto el asunto objeto de controversia como el posicionamiento inicial de las partes. En ellas, las partes recibirán información clara y precisa del procedimiento, de la dinámica de trabajo que se seguirá en caso de que finalmente se acuerde continuar la mediación y de sus beneficios frente a la vía judicial en cuanto a ahorro de tiempo y costes, para que, de este modo, puedan decidir acerca de la utilización de este mecanismo de resolución de controversias.

24. La mediación que se propugna no obliga a las partes en litigio a alcanzar ningún acuerdo. Constituye solo un requisito de procedibilidad, por lo que existe el riesgo de que dicha exigencia se convierta en un mero trámite burocrático que haga aumentar los trámites y plazos para la resolución de litigios ${ }^{59}$. Para evitarlo, el legislador debería establecer medidas disuasorias como también incentivadoras capaces de alentar y animar el recurso a la mediación, no solo como mero trámite, sino para la resolución del propio conflicto $^{60}$. Es cierto que el Anteproyecto de Ley ha previsto algunas medidas, a saber: considera la mediación como prestación incluida en el derecho a asistencia jurídica gratuita (art. 6.11 Ley de asistencia gratuita en su redacción dada por el Anteproyecto de Ley); excluye de la eventual condena en costas los derechos y honorarios devengados por abogado y procurador en caso de que no se haya acudido a un intento de mediación sin causa justa que lo hubiera impedido (art. 35.2 LEC en su redacción dada por el Anteproyecto de Ley) y establece que no habrá un pronunciamiento de costas a favor de la parte que no hubiera acudido a un intento de mediación sin causa justificada (arts. 394.1.3 y 539.2.2 LEC en su redacción dada por el Anteproyecto de Ley). Pero, a nuestro modo de ver, estas medidas resultan insuficientes ya que deberían venir acompañadas de otras como la reducción de tasas judiciales ulteriores, como ya se ha experimentado en Italia con resultados muy interesantes, e, incluso, la imposición de sanciones, como así sucede en otros países de nuestro entorno ${ }^{61}$, siempre que estas no supongan una limitación injustificada al principio de tutela judicial efectiva, según ha determinado el TJUE en la Sentencia de 14 de junio de 2017.

57 ScANNICCHIO, N., «L'adeguamento dell'ordinamento italiano alla nueva disciplina europea sulla risoluzione alternativa delle controversia di consumo", en ESTEBAN DE LA RosA, F., (ed.), La protección del consumidor en dos espacios de integración: Europa y América. Una perspectiva de Derecho internacional, europeo y comparado, Valencia, Tirant lo Blanch, 2015, pp. 683-686.

58 Herrera de las Heras, R., «La mediación obligatoria para determinados asuntos civiles y mercantiles», Indret, 2017, núm. 1, pp. 13-16.

59 Advirtiendo de este riesgo, véase el Informe del CGPJ, cit., nota 54, p. 22.

${ }_{60}$ En este mismo sentido, véase el Informe del CGPJ, cit., nota 54, p. 40.

${ }^{61}$ Véase el Informe realizado por la Comisión sobre la aplicación práctica de la Directiva 2008/52/ CE, del Parlamento Europeo y del Consejo, de 21 de mayo, sobre ciertos aspectos de la mediación en asuntos civiles y mercantiles [COM (2016) 542 final, Bruselas, 26 de agosto de 2016, p. 8]. 
25. A continuación nos centraremos en determinar hasta qué punto la mediación extrajudicial que el legislador español propone instaurar podría afectar a las relaciones de consumo, y de ser así, analizar si el modelo de cooperación que propone resulta incontestable y, además, compatible con el Derecho europeo y, en concreto, con el derecho a una tutela judicial efectiva.

\section{2. ¿Es viable la mediación extrajudicial de consumo en España?}

26. En España, la mediación se contempla como una institución que forma parte de nuestra cultura y forma de resolución de conflictos, aunque es la cultura judicial o del enfrentamiento la que está más arraigada. De ahí que resulte loable el intento del legislador español por potenciar esta forma de resolución de controversias en nuestro país. Ahora bien, según esta iniciativa legislativa no todas las materias pueden ser objeto de mediación extrajudicial. En concreto, el ámbito material de la misma se enmarca, fundamentalmente, en los ámbitos civil y mercantil ${ }^{62}$, aunque solo comprende a aquellos conflictos surgidos de relaciones personales o comerciales sostenidas en el tiempo (art. 6 del Anteproyecto de Ley) ${ }^{63}$. La lectura de este precepto nos lleva a concluir que esta iniciativa legislativa excluye a un número considerable de contratos de consumo al no incluir aquellos contratos de suministros de bienes y servicios celebrados en masa, como sucede en los contratos bancarios o los contratos de seguro, así como aquellos litigios de consumo que sean de escasa cuantía. Quizá esta exclusión se deba al deseo del legislador de fomentar el papel de las entidades RAL en este ámbito. No obstante, no excluye aquellos contratos de suministro de bienes y servicios que hayan sido objeto de negociación individual. Somos conscientes de que estaríamos hablando de supuestos muy reducidos e hipotéticos, pero, por esta razón, no puede considerarse que las relaciones de consumo hayan sido excluidas en su totalidad de dicha propuesta legislativa, lo que evidencia que el Derecho de consumo vuelve a ser el «talón de Aquiles» del legislador español en la regulación de

62 Sobre la necesidad de ampliar el ámbito de aplicación de esta iniciativa, véase el Informe CGPJ, cit., nota 54, pp. 32-33. Nótese, no obstante, que existen votos particulares en contra de la misma.

${ }^{63}$ A tenor del cual, «será necesario intentar la mediación antes de acudir a la vía judicial en los siguientes tipos de acciones: medidas que se adopten con ocasión de la declaración de nulidad del matrimonio, separación, divorcio o las relativas a la guardia y custodia de los hijos menores, alimentos reclamados por un progenitor contra el otro en nombre de los hijos menores (salvo que hubiera sido instruido con carácter previo un procedimiento por un delito relacionado con la violencia de género); responsabilidad por negligencia profesional; sucesiones; división judicial de patrimonios; conflictos entre socios y/o con los órganos de administración de las sociedades mercantiles; reclamaciones en materia de responsabilidad extracontractual que no traigan causa de un hecho de la circulación (protegidos por la Ley sobre responsabilidad civil y seguro en la circulación de vehículos a motor); alimentos entre parientes; propiedad horizontal y comunidades de bienes; derechos reales sobre cosa ajena; contratos de distribución, agencia, franquicia, suministro de bienes y servicios siempre que hayan sido objeto de negociación individual; reclamaciones de cantidades inferiores a 2.000 euros entre personas físicas cuando no traigan causa de un acto de consumo; defectos constructivos derivados de un contrato de arrendamiento de obra; protección de los derechos al honor, intimidad o la propia imagen; procesos arrendaticios que hayan de ventilarse por los cauces del juicio ordinario». 
la mediación. De hecho, el Consejo General del Poder Judicial (CGPJ) en su informe al Anteproyecto de Ley ha manifestado que:

«El catálogo de asuntos para los que el intento de mediación constituye un requisito de admisión de la demanda debería acomodarse a aquellos que contempla la Guía para la práctica de la mediación intrajudicial, que recoge los frutos de la experiencia acumulada desde los distintos sectores de la mediación durante muchos años» ${ }^{64}$.

Pues bien, si consultamos dicha Guía, puede observarse que entre los asuntos que pueden derivarse a mediación se encuentran aquellos que implican a consumidores frente a empresarios ${ }^{65}$.

Dicho esto, el que la mediación extrajudicial sea viable o no en el ámbito del Derecho de consumo dependerá de la decisión que finalmente adopte el legislador español. No obstante, si partimos, como hemos hecho, de la premisa de que resulta esencial la colaboración entre las entidades RAL y el sistema judicial, creemos que dicha iniciativa legislativa podría ser una gran oportunidad para imponer en las relaciones de consumo la operatividad de la mediación extrajudicial. Es más, creemos que resultaría oportuno y necesario imponer que dicha mediación - a la que estarían obligados a asistir los consumidores- se llevara a cabo por entidades RAL, más que por mediadores civiles y mercantiles carentes de formación específica al respecto.

27. En esta línea de pensamiento, resulta legítimo plantearse si, de prosperar nuestra propuesta, la mediación que propone el legislador español es, como bien indica la Memoria presentada por el Consejo General del Poder Judicial ${ }^{66}$, respetuosa con el marco interpretativo europeo fijado en la Sentencia dictada por el TJUE el 14 de junio de 2017. Es decir, resulta preciso determinar hasta qué punto la obligación de iniciar un procedimiento de mediación obligatoria antes de acudir a la vía judicial resulta compatible o no con el Derecho europeo y, en concreto, con el derecho a una tutela judicial efectiva. La respuesta a esta cuestión pasa por conocer cuál es el alcance de la obligación de mediar requerida ${ }^{67}$. No hay duda alguna de la compatibilidad existente entre el derecho a una tutela judicial efectiva y aquellos procedimientos en los que la mediación posee un carácter voluntario, como así sucede en el actual Derecho español. La situación es distinta cuando la mediación presenta un carácter obligatorio. En cuyo caso, es crucial conocer cuál es el alcance de la mediación a realizar. No pueden tratarse de la misma

\footnotetext{
${ }^{64}$ Véase el Informe CGPJ, cit., nota 54, p. 50.

${ }^{65}$ Guía para la práctica de la mediación intrajudicial, p. 30. Disponible en http://www.poderjudicial.es/cgpj/es/temas/mediacion/guia-para-la-practica-de-la-mediacion-intrajudicial/.

${ }^{66}$ Memoria del análisis de impacto normativo en el Anteproyecto de Ley de impulso de la mediación, https://www.mjusticia.gob.es/cs/Satellite/Portal/1292429062869?blobheader=application\%2F pdf\&blobheadername $1=$ Content - Disposition \&blobheadervalue $1=$ attachment $\% 3 B+$ filename\% 3 DMemor ia_de_Analisis_de_Impacto_Normativo_Mediacion.PDF.

${ }^{67}$ De Palo, G. y D'Urso, L., «Achieving a Balanced Relationship between Mediation and Judicial Proceedings", en The implementation of the Mediation Directive 29 November 2016. Disponible en http:// www.europarl.europa.eu/supporting-analyses, pp. 11-17.
} 
manera aquellos casos en los que es necesario que las partes sigan y paguen por un procedimiento de mediación completo de aquellos otros que, por el contrario, tienen la obligación, como así sucede en la iniciativa propuesta, por una sesión inicial, gratuita, para comprobar simplemente la idoneidad de seguir un proceso de mediación que evite el litigio ${ }^{68}$. No cabe duda de la legitimidad y compatibilidad de esta última exigencia con el derecho a la tutela judicial efectiva, donde la opción de acudir a la vía judicial queda intacta, como bien ha afirmado el TJUE en la Sentencia pronunciada el 14 de junio de 2017, mientras que no sucede lo mismo en el primer supuesto, es decir, cuando dicha obligación consiste en comparecer a un proceso de mediación.

No obstante, dicho requisito sí podría afectar al principio de tutela judicial efectiva, en la medida en que introduce una etapa adicional que debe observarse antes de poder acceder a la justicia. No obstante, los derechos fundamentales, como el propio Tribunal Constitucional (TC) ${ }^{69}$ considera, no constituyen prerrogativas absolutas, sino que pueden ser objeto de restricciones, siempre y cuando estas respondan a objetivos perseguidos de interés general. Como ya indicara el TJUE en la Sentencia dictada el 18 de marzo de 2010, la legitimidad de esta exigencia puede mantenerse, siempre y cuando:

«ello no implique un retraso sustancial a efectos del ejercicio de una acción judicial, interrumpa la prescripción de los correspondientes derechos, no ocasione gastos u ocasiona gastos escasamente significativos para las partes, y siempre y cuando la vía electrónica no constituya el único medio de acceder a ese procedimiento de conciliación y sea posible adoptar medidas provisionales en aquellos supuestos excepcionales en que la urgencia de la situación lo exija».

28. Para saber si el modelo propuesto en esta iniciativa legislativa resulta compatible con el marco normativo europeo y, en particular, con el derecho a una tutela judicial efectiva se impone concretar si esta cumple o no con los requisitos establecidos por el TJUE. A priori, el análisis de la mediación propuesta evidencia su compatibilidad con el principio de tutela judicial efectiva, puesto que las partes no tienen obligación de llegar a un acuerdo ${ }^{70}$. Estas solo deben participar en dos sesiones (informativa ${ }^{71}+$ exploratoria) que, para

68 Esteban DE la Rosa, F., «El régimen de la mediación de consumo», en Esteban DE la Rosa, F. (dir.) y OlARIU, O. (coord.), La resolución de conflictos de consumo. La adaptación del Derecho español al marco europeo de resolución alternativa $(A D R)$ y en Línea $(O D R)$, Navarra, Thomson Reuters-Aranzadi, 2018, pp. 107-124, esp. p. 117.

69 Eso parece deducirse del ATC 72/2016, de 12 de abril, pronunciado con ocasión del recurso de inconstitucionalidad interpuesto por el Gobierno contra la Ley 20/2014, de 29 de diciembre, de modificación de la Ley 22/2010, de 20 de julio, del Código de Consumo de Cataluña.

70 De hecho, el art. 20.2 Ley 5/2012 modificado por el Anteproyecto de Ley señala que, «celebrado el intento de mediación, los interesados podrán interponer la demanda declarativa, con independencia del estado en el que se encuentre la mediación».

71 El art. 17.2 Ley 5/2012 modificado por el Anteproyecto fija el contenido de la sesión informativa, en la que el mediador tiene que comunicar a las partes las posibles causas que puedan afectar a su imparcialidad, su profesión, formación y experiencia, las características de la mediación, su coste, la organización del procedimiento, las consecuencias jurídicas del acuerdo que se pueda alcanzar y el plazo para la firma del acta de la sesión constitutiva. 
que no suponga un retraso sustancial a la vía judicial, pueden desarrollarse en la misma, y su duración debe ser lo más breve posible. De hecho, según la normativa proyectada, este no podrá exceder de tres meses desde la recepción de la solicitud por el mediador (art. 6 del Anteproyecto de Ley). Es evidente que la compatibilidad de la regulación proyectada con el Derecho europeo y el principio a la tutela judicial efectiva exigirá un cumplimiento riguroso de dicho plazo.

Mediación y vía judicial se presentan, pues, complementarias en la diseñada propuesta legislativa y compatibles con el marco normativo europeo y las decisiones del TJUE. Con todo, sería preciso, en el caso de que fuere adoptada finalmente la propuesta que aquí se defiende, que el consumidor, sobre todo, en los supuestos transfronterizos fuera efectivamente informado de las consecuencias que puede acarrear su ausencia injustificada en la tramitación de tales sesiones. Es cierto que el art. 17.1 Ley 5/2012, en su redacción dada por el Anteproyecto de Ley, obliga al mediador a informar con claridad y precisión a los interesados de las consecuencias procesales que puede acarrearles su falta de asistencia no justificada a la sesión informativa, ya que puede afectar no solo a las costas derivadas del proceso, sino también a la inadmisión a trámite de la demanda posterior (art. 403 LEC en su redacción dada por el Anteproyecto de Ley). Dada, pues, la importancia que tiene el que el consumidor sea informado de ello, creemos que, en el ámbito de las reclamaciones de consumo transfronterizas, es necesario exigir que dicha información sea proporcionada al consumidor, para que llegue a comprender lo que se le está informando, en un idioma comprensible y accesible para él. Con la actual redacción no se garantiza dicha exigencia, lo que puede constituir un obstáculo de entidad considerable al derecho a la tutela judicial efectiva. Por lo que, de aceptarse la viabilidad de la mediación extrajudicial de consumo, debería de estipularse una previsión expresa en tal sentido.

Con todo, quedaría por determinar hasta qué punto la posibilidad de que sea inadmitida a trámite la posterior demanda judicial por no haber intentado — de forma injustificada- dicha mediación sería o no contraria al principio a una tutela judicial efectiva. Siguiendo las argumentaciones del TJUE en su Sentencia dictada el 18 de marzo de 2010, para que dicha medida fuera compatible debería perseguir un objetivo legítimo y justificado, no existir una alternativa menos severa y ser proporcional. A nuestro juicio, dicha sanción respondería a un objetivo legítimo, puesto que aspira a lograr una resolución más rápida y menos costosa de los litigios. Sería preciso, pues, verificar si habría otra alternativa menos severa a dicha sanción y, además, si habría proporcionalidad o no entre los objetivos perseguidos y los inconvenientes que eventualmente podrían ocasionarse con la inadmisión a trámite de la posterior demanda ${ }^{72}$.

29. A la luz de lo anterior cabe afirmar que la iniciativa proyectada cumple a grandes rasgos con las exigencias requeridas por el TJUE y, en particu-

72 Proponiendo soluciones alternativas, Merelles Pérez, M., «Comentarios al Anteproyecto de Ley de Impulso a la mediación», Diario La Ley, 2019, núm. 9.374, p. 8. 
lar, la que exige la prescripción de los correspondientes derechos, puesto que establece la obligación de suspender los plazos de prescripción o de la caducidad de las acciones desde la fecha en la que conste la redacción de dicha solicitud por el mediador. De forma que la reanudación de los plazos tendrá lugar desde que el mediador haya extendido el acta de conclusión del proceso de mediación (art. 4 Ley 5/2012 modificado por el Anteproyecto de Ley). Otra cosa es la preocupación que causa todo lo referente a la suspensión de las actuaciones, puesto que es un tema delicado que utilizado de forma abusiva puede suponer una ralentización de la resolución del litigio y, por tanto, una vulneración del derecho a una tutela judicial efectiva.

30. El TJUE exige también, para que dicho procedimiento previo resulte compatible, que no ocasione gastos, o que sean de escasa entidad. En el Anteproyecto de Ley no exige la presencia ni de abogado ni de procurador para asistir a la mediación y, además, se ha previsto la ampliación del derecho de asistencia jurídica gratuita para incluir en su ámbito material la intervención del personal mediador (art. 6.11 Ley 1/1996 en la redacción anteproyectada), por lo que, en principio, puede considerarse cumplido dicho requisito. No obstante, sería preferible una declaración expresa en dicho sentido. Además, sigue el TJUE, para que exista dicha compatibilidad debe poder solicitarse medidas cautelares. Es cierto que el art. 10 Ley 5/2012 establece que «durante el tiempo en que se desarrolle la mediación» no se puede ejercitar ningún tipo de acción judicial en relación con su objeto, salvo la petición de medidas cautelares u otras medidas urgentes y que, por su parte, el art. 722 LEC — en la redacción dada por el Anteproyecto de Ley_ regula la posibilidad de solicitar medidas cautelares por quien acredite ser parte de un pacto de mediación o de un proceso de mediación (en España o en el extranjero). Sin embargo, este precepto no se refiere, precisamente, a la posibilidad de solicitarlas con antelación al mismo procedimiento de mediación. No existe una regulación expresa. No obstante, desde una perspectiva puramente teórica y pese al silencio legal al respecto, esa posibilidad existe, pues así lo prevé el art. 730.2 LEC, siempre que el solicitante de las medidas cautelares acredite razones de urgencia o necesidad. Nos encontramos con una situación que, desde una perspectiva hipotética, podría llegar a suceder; sin embargo, desde un plano práctico, consideramos que difícilmente pudiera prosperar la solicitud de unas medidas cautelares preprocesales y premediales. No obstante, reconocemos que estas pueden concurrir y, por ende, no estaría de más que el legislador regulase dicha posibilidad concretando cómo, el cuándo y ante qué autoridad se pueden solicitar tales medidas, salvando, además, el requisito de la presentación en el plazo de veinte de días de la oportuna demanda que dispone el Derecho español (art. 730.2 LEC).

\section{CONCLUSIONES}

31. El análisis llevado a cabo en el presente trabajo nos puede conducir a algunas conclusiones destinadas a destacar los elementos no solo relevantes, 
sino decisivos, a efectos de conseguir cambios significativos en el modelo de resolución de litigios de consumo en nuestro país capaces de promover la necesaria confianza de los consumidores para dinamizar e impulsar la contratación de consumo. La Ley 7/2017 ha supuesto un paso significativo en esta dirección. No obstante, su promulgación ha sido solo el comienzo de un proceso en el que aún queda mucho por hacer. La normativa española no solo debe adaptarse por completo al marco normativo europeo, sino que además ha de completar el sistema diseñado en la propia ley.

Precisamente, hacia esta finalidad se orienta la Propuesta de Orden presentada por el Gobierno para la resolución alternativa de litigios en el ámbito del transporte aéreo. Su análisis nos lleva a concluir que la normativa proyectada responde esencialmente a las elementales exigencias de justicia, dando satisfacción a las derivadas de la Ley 7/2017, puesto que con ella se pretende garantizar a los consumidores el acceso a un sistema de resolución alternativa de litigios de alta calidad, imparcial, transparente, efectivo, rápido y justo, sin que ello suponga restringir el acceso a los órganos jurisdiccionales.

No obstante, cabría proponer la modificación de algunos aspectos para así lograr una perfecta adaptación a las exigencias del Derecho de la Unión Europea y de la Ley 7/2017. Sería preciso ampliar el ámbito de aplicación espacial de dicha iniciativa legislativa, puesto que la perspectiva acogida en la misma no responde a lo establecido en el Derecho europeo. Para que ello fuera así, la AESA debería tener competencia para conocer de aquellos litigios en los que el consumidor reside en un Estado miembro de la Unión Europea frente a un empresario establecido en otro Estado. De esta manera se minimizaría uno de los problemas fundamentales que pueden surgir en este ámbito y que tienen que ver con la dificultad que existe para concretar cuál es la autoridad competente para conocer de los conflictos que puedan surgir.

Otra de las críticas que cabe hacer a la normativa proyectada es que no defina las relaciones que pudieran existir entre el procedimiento auspiciado y aquellos otros métodos de resolución de controversias que resultan compatibles con este. Se trata de una cuestión que, a nuestro juicio, debería ser resuelta en la normativa propuesta para evitar en el futuro posibles problemas prácticos.

Además, sería oportuno que la Propuesta de Orden fuera reformada a efectos de garantizar el cumplimiento efectivo de los principios de imparcialidad, eficacia y equidad que la Ley 7/2017 establece, como también sería aconsejable que aclarara que los litigios de los que derivan las reclamaciones en este ámbito pueden haber surgido en línea o no. Con todo, la efectiva protección del consumidor requiere de más recursos humanos y materiales. De no ser así, la eficacia y efectividad del procedimiento que ha diseñado el legislador en esta Propuesta legislativa quedará comprometida.

32. Somos conscientes y partidarios de la necesidad de colaboración entre entidades RAL y los sistemas judiciales para que los métodos alternativos de resolución de conflictos se perfilen como unos medios adecuados a los 
que se puede acudir para resolver un litigio de consumo. No es posible constituir un nuevo sistema de resolución de controversias en las reclamaciones de consumo sin fomentar el diálogo o la sinergia entre las entidades RAL y los sistemas judiciales. Por ello, estamos convencidos que el Anteproyecto de Ley de impulso a la mediación presentado por el legislador español, donde aboga por un sistema de «mediación obligatoria mitigada», representa una oportunidad idónea para conseguirlo. Un modelo de mediación que, como hemos demostrado, no vulnera ni el principio de autonomía de la voluntad ni el de la tutela judicial efectiva, puesto que la mediación que se propugna no obliga a las partes en litigio a alcanzar ningún acuerdo. Aunque hay, como hemos demostrado, margen para su mejora.

Con todo, la mediación así propuesta puede jugar un rol decisivo para contribuir a facilitar la resolución de litigios surgidos en el ámbito del Derecho de consumo. De hecho, si tenemos en cuenta el papel que en esta clase de litigios están desempeñando en la actualidad las entidades RAL acreditadas, creemos que resultaría de interés imponer que dicha mediación fuera llevada a cabo por las entidades RAL, más que por mediadores civiles y mercantiles carentes de formación específica al respecto. Al legislador español le queda pendiente, pues, tomar una decisión fundamental y esperemos que sea en el sentido propuesto en el presente trabajo. Estaremos, por tanto, atentos a la futura ley.

\section{RESUMEN}

\section{EL MARCO REGULADOR EN PROYECTO EN ESPAÑA PARA LA RESOLUCIÓN ALTERNATIVA DE CONFLICTOS: ¿NUEVAS PERSPECTIVAS PARA LAS RECLAMACIONES DE CONSUMO?}

Con la Ley 7/2017, el legislador pretende favorecer el desarrollo y cualificación de los sistemas de resolución alternativa de litigios de consumo para promover la confianza de los consumidores, aunque esta tarea todavía no ha acabado. Prueba de ello es la iniciativa legislativa presentada por el legislador español para resolución de conflictos en el ámbito del transporte aéreo en la que se diseña un procedimiento ad hoc para este tipo de reclamaciones. Su valoración general, aunque positiva, es susceptible de mejora para su completa adaptación al Derecho europeo y a la Ley 7/2007.

Con todo, creemos que es necesario que el legislador español apueste por el desarrollo de vías de actuación conjuntas y coordinadas entre las entidades RAL y el sistema judicial. La confianza del consumidor sería mayor si las entidades RAL ayudaran a facilitar la resolución de litigios en la vía judicial. El nuevo Anteproyecto de Ley de impulso a la mediación parece ser, pues, una oportunidad única para materializar dicho propósito, al optar por un cambio de modelo orientado hacia el de la «mediación obligatoria mitigada». Un modelo que, como hemos demostrado, no vulnera ni el principio de autonomía de la voluntad ni el de la tutela judicial efectiva. Además, creemos que esta iniciativa legislativa podría ser una gran oportunidad para contribuir a facilitar la resolución de litigios surgidos en el ámbito del Derecho de consumo. No obstante, se trata de una iniciativa en la que hay margen para la mejora.

Palabras clave: resolución alternativa de litigios, Derecho europeo, Derecho español, reclamaciones en el sector del transporte aéreo, mediación extrajudicial de consumo. 


\section{ABSTRACT \\ THE REGULATORY FRAMEWORK PROJECT IN SPAIN FOR ALTERNATIVE CONFLICT RESOLUTION: NEW PROSPECTS FOR CONSUMER CLAIMS?}

With Law 7/2017, the legislator intends to favor the development and qualification of alternative consumer dispute resolution systems to promote consumer confidence, although this task has not yet finished. Proof of this is the legislative initiative presented by the Spanish legislator for conflict resolution in the field of air transport and in which an ad hoc procedure is designed for this type of claims. Its general assessment, although positive, is susceptible to improvement for its complete adaptation to European Law and Law 7/2007.

However, we believe that it is necessary for the Spanish legislator to bet on the development of joint and coordinated channels of action between the RAL entities and the judicial system. Consumer confidence would be greater if the RAL entities help facilitate the resolution of litigation in the judicial process, and the new Draft Law to promote mediation seems to be the opportunity to materialize this purpose, by opting in this area for a change of model oriented towards the «mitigated mandatory mediation». A model of mediation that, as we have shown, does not violate either the principle of autonomy of the will or that of effective judicial protection. In addition, we believe that this legislative initiative could be a great opportunity to help facilitate the resolution of litigation arising in the field of consumer law. However, it is an initiative in which there is scope for improvement.

Keywords: alternative litigation resolution, European law, Spanish law, claims in the air transport sector, extrajudicial consumer mediation. 